\title{
Remembering eventful and uneventful word presentations
}

\author{
JOHN M. GARDINER \\ The City University, London, England \\ and \\ MICHAEL J. WATKINS \\ Princeton University, Princeton, New Jersey 08540
}

\begin{abstract}
Recognition memory for a list of words was greatly enhanced when each word was presented along with the object it denoted and some relevant activity and comment by the experimenter. It is argued that this finding highlights the need for theory of memory to deal directly with presentation eventfulness.
\end{abstract}

Much of human memory research consists in the presentation of a list of words and then a test to ascertain which words are remembered as having occurred in the list. The use of such procedures carries with it the danger of memory theory giving undue emphasis to the retention and recollection of words qua words, rather than focusing on word presentation. This danger is illustrated by certain theories that were dominant a few years ago. According to these theories, the presentation of a word in a list leads to an "occurrence tag" being attached to the representation of the word in a permanent knowledge structure (Anderson \& Bower, 1972; Kintsch, 1970).

More recently, the limitations of simple "tagging theories" have become apparent. Theorists now place more emphasis on the notion that each presentation of a word is a unique event, or episode, in the personal experience of the subject participating in the experiment (Tulving, 1972). This brief article describes a study that underscores the value of this shift in theoretical perspective. But the point of the article is to argue that the shift in perspective has not gone far enough.

The study extends previous research which has shown that presenting objects, or pictures of objects, leads to a higher level of recall than presenting merely the objects' names (Bevan \& Steger, 1971). Encountering objects or pictures may be thought of as more eventful than encountering words. The present experiment was designed to demonstrate the importance of eventfulness in the presentation episode in a more dramatic way. Word recognition following conventional list presentation was compared with that following highly

This research was conducted while John M. Gardiner was on leave at the University of Toronto and supported by the National Research Council of Canada Grant A8632 to Endel Tulving. Reprint requests may be sent to $M$. J. Watkins at the Department of Psychology, Princeton University, Princeton, New Jersey 08540. embellished presentation. That the test was of recognition is important: If it is "words" that are being remembered, rather than word events, it is difficult to see how embellishing their presentation could raise performance relative to that attained under conditions of free and undistracted study of the very words themselves.

\section{METHOD}

\section{Subjects}

Thirty-six volunteers whose ages ranged from 16 to about 40 years participated for pay. They were assigned arbitrarily to one of two groups, and they were tested individually or two or three at a time.

\section{Material}

For stimulus material, 200 commonplace objects were collected. They included such things as a piece of string, some buttons, a dollar bill, a blotter, a cigar, a bottle, and a knife. The names of these objects were allocated arbitrarily to one of two sets of 100 words, one set for use as the presentation list, the other as "lures" in the recognition test. The "target" words were printed one to a flash card for presentation in the study phase; the cards were randomly ordered to form a single presentation list. The names of all 200 objects were separately randomized to form the recognition test list.

\section{Procedure}

The 18 subjects in each group were presented with the sequence of 100 words and told that they would subsequently be asked to recognize them. For the control subjects, whom we call the "word group," conventional presentation procedures were used. The flash cards were presented at the rate of one every $10 \mathrm{sec}$ and the experimenter read each word aloud as it was presented. For the other subjects, whom we call the "action group," the words were presented in the same way and at the same rate, but, in addition, the experimenter produced an instance of the object denoted by the word, briefly commented on it, and performed some appropriate action. A few examples will illustrate this procedure. BLOTTER: The experimenter said "a large blue one, virtually unmarked, if it's been used at all it must have been for invisible ink," and the experimenter mimed the action of writing; STRAW: "an articulated version, so that one can drink around corners," and the experimenter 
bent the straw; BUCKET: "reminds me of old vaudeville routines, slapstick comedy, Laurel and Hardy," and the experimenter placed his foot in it. Each object was handed to the experimenter by a behind-the-scenes assistant and returned directly after its presentation.

Immediately after the presentation phase, all subjects were engaged in lighthearted conversation for $5 \mathrm{~min}$, and then given a conventional recognition test. The subjects were told to work through the test list at their own pace, circling each word that they thought had occurred earlier. The entire experimental session lasted for about $30 \mathrm{~min}$.

\section{RESULTS AND DISCUSSION}

The mean proportion of recognition errors for each group is shown in Figure 1. Clearly, the word group missed more targets and circled more lures than the action group. This pattern of results is just as clear when the data are summarized by medians rather than by means. The median miss rate was 32.5 in the word group, and 6.3 in the action group; the false positive rates were 4.3 and 0.0 , respectively. The difference in the miss rates was significant by two-tailed MannWhitney U-test $(U=52.0, p<.001)$, as was the difference in the false positive rates $(U=68.5, p<.005)$.

These results show that subjects allowed free and undistracted study of each word presentation in preparation for the upcoming test were likely to make far more recognition errors than subjects who experienced the more dramatic presentation episodes. This outcome highlights a problem for theory of memory. The problem is the need to develop and incorporate a construct that permits the effects of the eventfulness of a presentation episode to fit readily into the theoretical scheme of things. We believe that theory will not provide a good account of simple observations like the one reported here until it addresses the issue of episodic eventfulness directly.

Certain more elaborate and comprehensive theories can, of course, accommodate such findings (Anderson, 1976; Anderson \& Bower, 1974). But they can do so

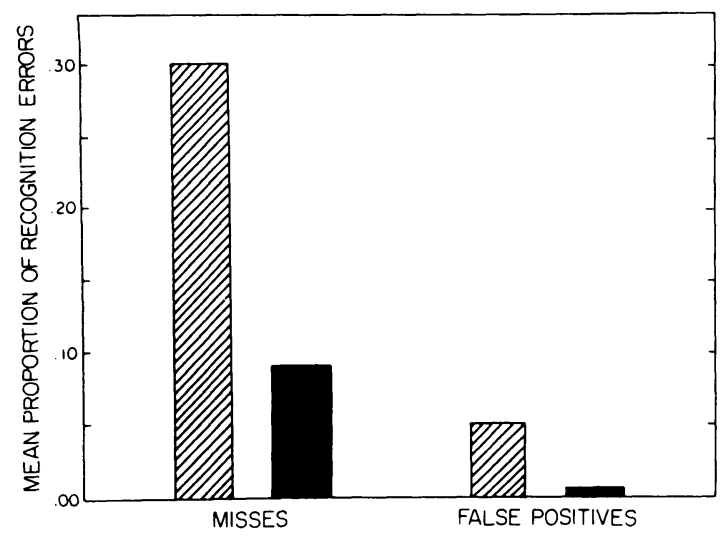

Figure 1. Mean proportion of misses and false positives for the action group (solid bars) and for the word group (striped bars). only by virtue of their complexity and through the use of post hoc assumptions. Theories of this kind could have given a ready account of our results regardless of how they had turned out.

One theoretical notion that takes us some way toward accounting for the effects of presentation eventfulness is "depth of processing," where greater depth implies a greater degree of cognitive analysis (Craik \& Lockhart, 1972). The idea here is that the perceptual-cognitive processing afforded a word event can vary, and the memory trace is conceptualized as being a by-product of the processes carried out in the interpretation of the event: The deeper the level of processing, the more durable the memory trace. This notion has found its strongest support in "incidental learning" research, which shows that memory for word presentations is sharply dependent upon the way they are attended (e.g., Hyde \& Jenkins, 1973). In these studies, rather than being told to "learn" the words presented, the subjects are typically given an "orienting" task that requires them to make particular decisions about the words. The general finding is that subjects are more likely to remember the earlier occurrence of the words after tasks that demand more cognitive, semantic decisions than after those that do not. Indeed, semantic orienting tasks have often been found to be as effective as instructions to learn (cf. Mandler, 1967; Postman, 1964). Although the present findings can be described in terms of depth of processing, with the more eventful presentations giving rise to deeper processing, this interpretation is not compelling. The relation between depth of processing and eventfulness is uncertain. It is not clear, for instance, that making a decision about the semantic characteristics of a word is any more or less eventful than deciding whether the word contains a particular letter of the alphabet.

A variant of the depth of processing construct that relates more closely to the notion of eventfulness is the concept of "breadth" or "spread" of encoding (Craik \& Tulving, 1975). Here, the idea is that the durability of the memory trace depends not only on the depth of processing attained but also on the number of encoded features or the extent to which more elaborate encoding occurs. It is reasonable to suppose that the presentations to our action group resulted in more elaborate encoding than those to our word group. But this concept, too, does not really encapture the eventfulness of an episode. In particular, this is partly because the concept of breadth, like that of depth, has been pinned to encoding operations induced by the nature of the mental task given to the subject. Also, quite discrete environmental events may sometimes be remembered much better than events that are crowded with incident. Some events are more momentous than others.

Our results show that, even in an intentional learning situation, subjects are normally unable to encode a bland 
event as effectively as an eventful one. This outcome suggests that an adequate conception of eventfulness will have to refer to the impact of environmental activity on mental operations. In incidental learning studies, environmental activity is held constant; only the mental task of the subject is manipulated. The results of those studies establish that memory performance varies considerably with the nature of the task and the mental operations it induces. But our results show that enriched environmental activity engages mental operations whose memorial consequences transcend those tapped by task manipulations.

In conclusion, this simple study underscores an emergent consensus among memory theorists that "events are primary" (Jenkins, 1977). More important, the study highlights the need for a construct that would enable theory of memory to say why some events are more primary than others.

\section{REFERENCES}

Anderson, J. R. Language, memory, and thought. Hillsdale, N.J: Laurence Erlbaum, 1976.

Anderson, J. R., \& Bower, G. H. Recognition and retrieval processes in free recall. Psychological Review, 1972, 79, 97-123.

ANDERson, J. R., \& Bower, G. H. A propositional theory of recognition memory. Memory \& Cognition, 1974, 2, 406-412.
Bevan, W., \& Steger, J. A. Free recall and abstractness of stimuli. Science, 1971, 172, 597-599.

CRAIK, F. I. M., \& Lockhart, R. S. Levels of processing: A framework for memory research. Journal of Verbal Learning and Verbal Behavior, 1972, 11, 671-684.

Craik, F. I. M., \& Tulving, E. Depth of processing and the retention of words in episodic memory. Journal of Experimental Psychology: General, 1975, 104, 268-294.

Hyde, T. S., \& Jenkins, J. J. Recall for words as a function of semantic, graphic, and syntactic orienting tasks. Journal of Verbal Learning and Verbal Behavior, 1973, 12, 471-480.

JEYKINS, J. J. Remember that old theory of memory? Well, forget it! In R. Shaw \& J. Bransford (Eds.), Perceiving, acting, and knowing: Toward an ecological psychology. Hillsdale, N.J: Laurence Erlbaum, 1977.

KintsCH, W. Models for free recall and recognition. In D. A. Norman (Ed.), Models of human memory. New York: Academic Press, 1970.

MANDLER, G. Organization and memory. In K. W. Spence \& J. T. Spence (Eds.), The psychology of learning and motivation (Vol. 1). New York: Academic Press, 1967.

Postman, L. Short-term memory and incidental learning. In A. W. Melton (Ed.), Categories of human learning. New York: Academic Press, 1964.

Tulving, E. Episodic and semantic memory. In E. Tulving \& W. Donaldson (Eds.), Organization of memory. New York: Academic Press, 1972.

(Received for publication September 28, 1978.) 